\title{
Effects of Male Selection for Body Weight on Performance of Offsprings in Broiler Pure-Lines
}

\section{-Author(s)}

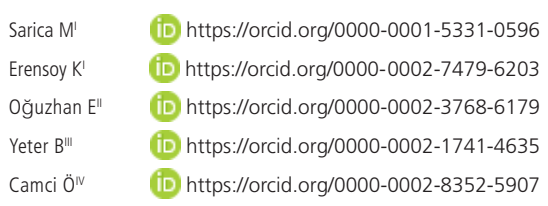

Ondokuz Mayis University, Agricultural Faculty, Department of Animal Science, 55139 Atakum/ SAMSUN, Turkey.

" Republic of Turkey Ministry of Agriculture and Forestry, Geçit Kuşağı Agricultural Research Institute, 26200 Tepebaşı/ESKIŞEHIR, Turkey.

III Kahramanmaras Sutcu Imam University, Agricultural Faculty, Department of Animal Science, 46050 Onikişubat/KAHRAMANMARAŞ, Turkey.

v Cyprus West University, İsmet Inönü Ave 29, 99450 Gazimağusa/KIBRIS, Turkey.

\section{Mail Address}

Corresponding author e-mail address Kadir Erensoy

Ondokuz Mayis University, Agricultural Faculty, Department of Animal Science, 55139

Atakum/SAMSUN, Turkey.

Phone: +90 362312 1919/1442

Email: kadir.erensoy@omu.edu.tr

\section{- Keywords}

Broiler, pure lines, body weight, feed conversion ratio, selection.

\section{ABSTRACT}

This study aimed to determine the effects of the variation in body weight (BW) in pure lines even after selection on the BW and feed conversion ratio $(F C R)$ of offsprings in broiler pure-lines. The males of the dam (A1) and sire (B1) line were grouped according to their BW after selection at the $6^{\text {th }}$ and $12^{\text {th }}$ weeks of age. In the sire lines, the heaviest males at six weeks of age were selected (300), and the selected males were divided into three groups in terms of BW as average (B11: 100 males), high (B12: 100 males), and the highest (B13: 100 males). In the dam lines, the selected males were divided into three groups as an average (A11: 100 males), low (A12: 100 males), and high BW (A13: 100 males). In the dam line, offsprings of males with average and high BW had the highest BW at 42 days of age compared to the low BW group $(p<0.05)$. However, there was no statistically significant difference in BW between the BW groups in the offsprings of the sire line. Offsprings of dam line males with average and higher than average BW had better FCR values. However, there was no significant change in FCR between the offsprings of the sire line BW groups. As a result, it is thought that by preserving the variation at a certain level in future generations, a significant improvement can be achieved in the BW and FCR by selecting heavier males.

\section{INTRODUCTION}

Selection for body weight (BW) and feed conversion ratio (FCR) have attracted great attention in the poultry industry due to their economic and environmental effects (Mebratie et al., 2019). Genetic selection programs have led to an increase in the growth rate and meat yield in broilers from the mid-20th century, and significantly reducing the slaughter age and the amount of feed and energy required to reach slaughter weight (Tallentire et al., 2016; Muth \& Zarate, 2017; Hartcher \& Lum, 2020). Broiler breeding process is carried out with a pyramidal structure and there are parental pure-lines on the top of this pyramid. Breeding of broilers is completed at the pure-line stage and genetic progress is achieved at this stage in terms of the desired traits (Leeson \& Summers, 2010). The most important breeding goal is to obtain the highest heterosis in crossing systems used in hybrid production (Türkoğlu \& Sarıca, 2018). Firstly, general combining ability is developed with a strong selection on pure-lines. Then, the specific combining ability of the lines developed in this way in crossing systems in different combinations are tested and the most appropriate pureline combinations for the hybrid production model are determined (van Grevenhof \& Van der Werf, 2015; Türkoğlu \& Sarıca, 2018; Calus et al., 2019). The most emphasized breeding traits in broilers are fast growth and the highest BW is taken into account in selecting the males in dam and sire lines. It is known that there is a strong genetic correlation 
with their offspring in terms of BW in the sire lines, and the offsprings produced from the sires selected for high BW have better live weight than average. BW heritability is $0.30-0.40$ for BW gain. Heavier offspring are produced from males with higher BW. However, even after selection, BW-related variation continues among the best fathers (Leeson \& Summers, 2010). In this study, the males belonging to the dam (A1) and sire (B1) line were grouped according to their BW after selection on the $6^{\text {th }}$ and $12^{\text {th }}$ weeks of age. This study aimed to determine the effects of the variation in BW in pure-lines even after selection on the BW and feed conversion ratio of offsprings in broiler pure-lines.

\section{MATERIAL AND METHODS}

The study was conducted on a dam (A1) and a sire line (B1) whose breeding process were carried out in "Eskişehir Geçit Kuşağı Agricultural Research Institute." In the sire line (B1), male and female chickens are selected gradually in the BW and breast width direction on the $6^{\text {th }}, 12^{\text {th }}$ and $16^{\text {th }}$ weeks of age. Besides, male broilers are used in selection by performing an individual FCR test between the $6^{\text {th }}$ and $8^{\text {th }}$ weeks of age. In each period, 200 males and 400 females are selected from approximately 1200 females and 1000 males, one male and nine females are divided into male families (40-50 families) and kept in the egg production period until the $45^{\text {th }}$ week of age. According to the fertility selection in males, the next generation is produced from 30 families with the best fertility.

In the final selection of the dam line, the 35-week egg production at the family level (100-110 families) and the production of the next generation are provided from families with the best egg production.

In this study, BW grouping was applied for males to be mated with dam and sire line females. In the sire lines, the heaviest males on the $6^{\text {th }}$ week of age were selected (300) and wing numbers were attached. The selected males were divided into three groups in terms of BW as average (100 males), high (100 males) and the highest (100 males). Following the selection criteria in later ages, 12 families were formed from males with the average BW (B11), 20 families from males with high BW (B12), and 12 families from the highest BW (B13) males, and the females were randomly distributed to all families.

Considering the reproductive traits in the dam lines, the average live weight at six weeks of age was considered in the selection for BW. The selected male chickens were divided into three groups, with an average BW (A11: 100 males), low BW (A12: 100 males) and high BW (A13: 100 males). Among these, 40 males from each group that passed all the selection steps were used for mating.

Hatching eggs (400 eggs in each weight group) collected by sire and dam lines of BW groups were incubated at the $40^{\text {th }}$ week of the laying period and the chicks were compared in terms of broiler performance. In the study where the standard broiler production system was applied, four replications were formed in $1.8 \times 2.2 \mathrm{~m}$ floor pens and 24 chicks were placed in each pen ( 6 chicks $\left./ \mathrm{m}^{2}\right)$.

The growing, rearing and laying periods of pure lines were carried out in closed and environmentally controlled poultry houses. The broiler tests were carried out in a house with window, automatic heating and ventilation system. Water and feed were also given ad-libitum during the whole experiment period. The feeds were obtained from a commercial firm and the nutritional content of feeds are given in Table 1.

Hatching eggs, chick weight, body weights on the 1 through the $6^{\text {th }}$ weeks of age and weekly additive FCR levels were determined in the study. According to the male BW groups formed on the dam and sire lines, the performance of offsprings was evaluated separately.

\section{Statistical analyses}

One-way analysis of variance was used to compare the BW of the groups, and the Duncan test was used

Table 1 - The nutritional content of feeds used in the study.

\begin{tabular}{|c|c|c|c|c|}
\hline Nutrients & $\begin{array}{c}\text { Broiler chick starter } \\
\text { (1-7 days) }\end{array}$ & $\begin{array}{l}\text { Broiler chick } \\
\text { (8-28 days) }\end{array}$ & $\begin{array}{l}\text { Broiler chicken } \\
\text { (29-35 days) }\end{array}$ & $\begin{array}{c}\text { Broiler finisher } \\
\text { (36-42 days) }\end{array}$ \\
\hline Crude protein (\%) & 23.00 & 22.00 & 21.00 & 18.00 \\
\hline ME (kcal/kg) & 3000 & 3100 & 3100 & 3100 \\
\hline Crude cellulose (\%) & 4.00 & 4.00 & 4.00 & 6.00 \\
\hline Crude ash (\%) & 5.00 & 5.00 & 5.00 & 5.00 \\
\hline $\mathrm{Ca}(\%)$ & 1.00 & 0.95 & 0.80 & 0.80 \\
\hline Phosphorus (\%) & 0.50 & 0.50 & 0.45 & 0.60 \\
\hline Methionine (\%) & 1.00 & 0.45 & 0.40 & 0.40 \\
\hline Lysine (\%) & 1.35 & 1.20 & 1.10 & 1.00 \\
\hline
\end{tabular}


to compare the means. The data were analyzed with SPSS (Version 21) statistical package program. In addition, coefficients of variation (CV\%) were used to determine the uniformity of the offsprings ( $C V=\sigma / \mu$ $\times 100 \%$; $\sigma$ : the standard deviation and $\mu$ : the mean).

\section{RESULTS AND DISCUSSION}

Chick weight is nearly $65 \%$ of the egg weight at the beginning of incubation (Sutherland et al., 2018; Türkoğlu \& Sarıca, 2018). The effect of maternal factors resulting from egg weight on chick weight decreases as the growth period progresses and almost disappears by the age of 6-8 weeks (Wilson, 1991). While there was no difference between the offsprings of the BW groups in terms of egg and chick weights in the dam lines, differences occurred when they reached 7 days of age $(p<0.05)$. Egg weight, chick, and 7-d BW differed between the BW selection groups offsprings $(p<0.05)$ and there was no difference between the groups from 14 to 42 days of age. It is thought that maternal factors rather than genetic selection are effective on BW at 7 days of age. It is understood that maternal effects disappeared due to the lack of BW differences between the groups at 14, 21, 28 and 35 days of age (Wilson, 1991; Jiang \& Yang, 2007).

In the dam line, offsprings of males with average and high BW had the highest BW at 42 days of age compared to the low BW group $(p<0.05)$ and $2657.5,2594.3$ and $2313.6 \mathrm{~g}$ were determined respectively (Table 2 ).
However, although there was no statistically significant difference in BW between the selection groups in the sire line, the offsprings of the B13 males showed higher BW numerically (Table 3). A different way was followed in creating the dam line BW selection groups compared to the sire line. While low, average and high BW selection groups were formed in the dam line, the sire line was grouped only according to the BW of the males above the average. This situation caused a wider variation in the dam line and the group averages had values far from each other. In the sire line, the genetic variation remained low as the averages of the BW groups formed were closer than the dam line. For this reason, while statistical differences occurred between the offsprings BW at 42 days of age in the dam line, only numerical differences occurred in the sire line.

Market age of broiler chickens has decreased between 35-42 days of age today. In order to reach the desired slaughter weight at these ages, an intensive selection is applied in terms of BW, especially in the males of the dam and sire lines (Flisar et al., 2014; Türkoğlu \& Sarıca, 2018). In our study, the selection at the level of $40 \%$ was applied to dam line males for each BW group. In the sire lines, 12\%, 20\% and 12\% of the males with the highest BW were selected in B11, B12 and B13 groups, respectively. It is stated that there is a variation in growth traits among males even after selection, and by taking advantage of this variation, offsprings with better BW can be obtained. However, heavier offsprings can be produced by selecting

Table 2 - Effects of BW selection in dam line males at 6 and 12 weeks on offsprings BW (g).

\begin{tabular}{lcccccccc}
\hline BW groups & EW & CW & $7 d$ & $14 d$ & $21 d$ & $28 d$ & $35 d$ & $42 d$ \\
\hline A11 & 64.2 & 43.3 & $132.3^{\mathrm{b}}$ & 424.8 & 833.7 & 1357.6 & 1989.3 & $2657.5^{\mathrm{a}}$ \\
$\mathrm{A} 12$ & 63.9 & 43.4 & $132.1^{\mathrm{b}}$ & 433.5 & 839.1 & 1327.1 & 1941.5 & $2313.6^{\mathrm{b}}$ \\
$\mathrm{A} 13$ & 64.3 & 43.6 & $140.3^{\mathrm{a}}$ & 417.5 & 834.2 & 1341.3 & 1960.8 & $2594.3^{\mathrm{a}}$ \\
SEM & 0.137 & 0.189 & 1.266 & 3.866 & 4.766 & 12.814 & 25.419 & 35.667 \\
F values & 0.484 & 0.203 & 4.747 & 1.453 & 0.083 & 0.356 & 0.219 & 4.654 \\
\hline$p$ values & 0.617 & 0.816 & 0.010 & 0.318 & 0.921 & 0.717 & 0.811 & 0.011 \\
\hline
\end{tabular}

A11: Chickens from males with average BW; A12: Chickens from males with low BW; A13: Chickens from males with high BW; EW: Egg weight; CW: Chick weight; d: days of age.

a,b: The differences between the means shown with different letters in the same column are significant.

Table 3 - Effects of BW selection in sire line males at 6 and 12 weeks on offsprings BW (g).

\begin{tabular}{lcccccccc}
\hline BW groups & EW & CW & $7 d$ & $14 d$ & $21 d$ & $28 d$ & $35 d$ & $42 d$ \\
\hline B11 & $62.0^{c}$ & $42.3^{c}$ & $114.1^{\mathrm{b}}$ & 374.5 & 781.2 & 1328.4 & 2045.9 & 2738.5 \\
B12 & $63.9^{\mathrm{a}}$ & $44.5^{\mathrm{a}}$ & $115.0^{\mathrm{b}}$ & 378.9 & 789.1 & 1385.3 & 2139.6 & 2792.6 \\
B13 & $63.1^{\mathrm{b}}$ & $43.3^{\mathrm{b}}$ & $119.4^{\mathrm{a}}$ & 393.0 & 799.4 & 1373.0 & 2068.7 & 2826.0 \\
SEM & 0.162 & 0.191 & 0.859 & 5.462 & 8.240 & 18.473 & 27.926 & 46.211 \\
F values & 11.501 & 11.558 & 3.764 & 1.067 & 0.341 & 0.841 & 1.033 & 0.310 \\
\hline$p$ values & 0.000 & 0.000 & 0.025 & 0.401 & 0.724 & 0.476 & 0.411 \\
\hline
\end{tabular}

B11: Chickens from males with average BW, B12: Chickens from males with high BW, B13: Chickens from males with the highest BW; EW: Egg weight; CW: Chick weight; d: days of age.

$a, b, c:$ The differences between the means shown with different letters in the same column are significant. 
heavier males (Leeson \& Summers, 2010; Uçar, 2020). While this situation was evident in the dam line in our study, it was observed that there was a tendency to obtain heavy offsprings from heavy males in the sire line (Table 2; Table 3).

No significant differences were found between offsprings obtained from BW groups in dam and sire lines in terms of BW variations at 42 days of age $(p<0.05$; Figure 1). However, numerically, it was determined that there was a higher variation in A12 broilers than in $A 11$ and $A 13$ groups. While the coefficient of variation was $20.7 \%$ in A12 broilers, it was calculated as $13.1 \%$ in $A 11$ and $A 13$ broilers. No significant difference was found between the sire line BW groups in terms of BW variation at 6 weeks of age ( $p>0.05)$. The coefficient of variation was determined as $21.4 \%, 18.5$ and $14.9 \%$ in the B11, B12 and B13 groups, respectively.
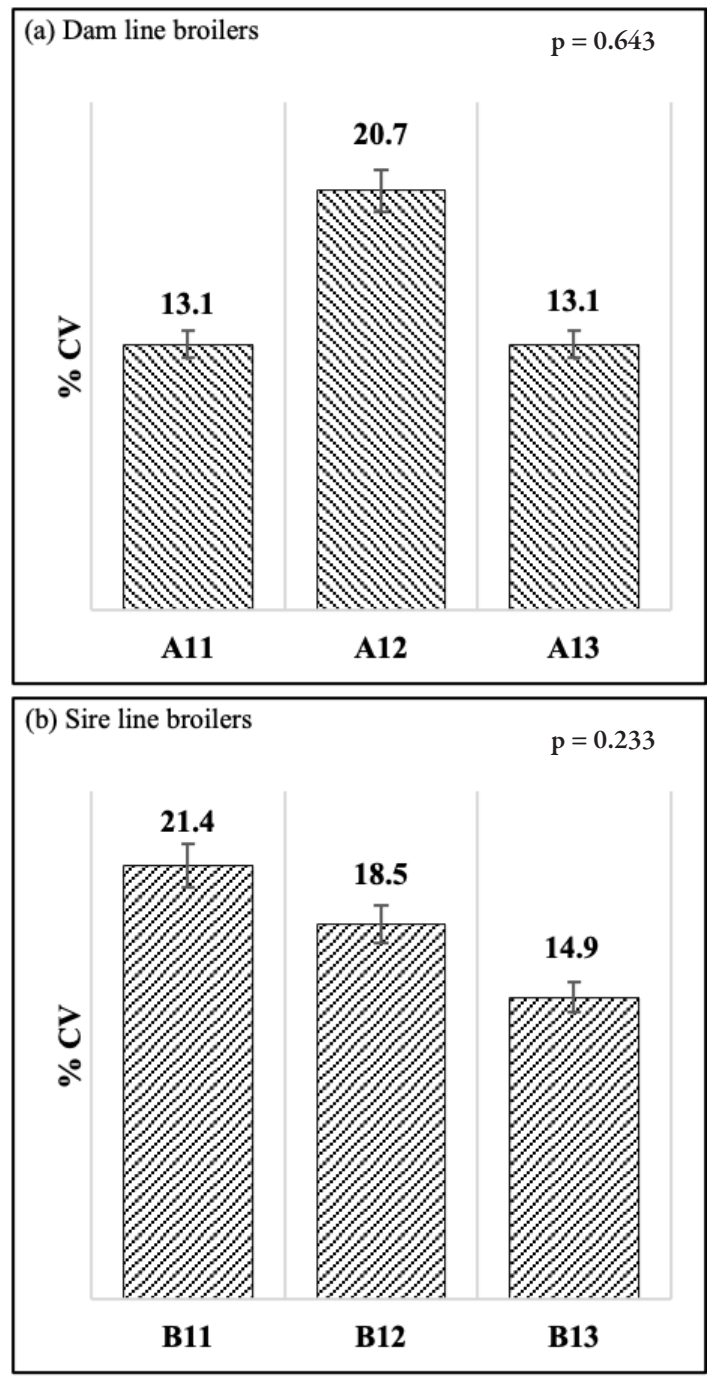

Figure 1 - Variation coefficients (CV) in dam (a) and sire (b) line broilers at 6 weeks of age (\%).

A11: Chickens from males with average BW; A12: Chickens from males with low BW; A13: Chickens from males with high BW; B11: Chickens from males with average BW, B12: Chickens from males with high BW, B13: Chickens from males with the highest BW.
The findings obtained in Figure 1 are considered important in terms of showing the effect of BW selection and grouping in males on the BW variation level in offsprings. Generally, the variation in gene frequencies decreases in response to genetic selection, but this reduction occurs to a small extent over the first few generations, and gene frequencies change slowly unless genes with large effects are present. Although the outcome of the long-term selection is difficult to predict, gene frequencies that change in response to selection depend on the traits of individual genes and the new variation caused by the mutation (Falconer \& Mackay, 1996). Genetic variance for the growth rate of broiler chickens does not decrease significantly even after a few generation selections due to the formation of new genetic variation (mutation and recombination) and epistatic effects (Sorensen, 1986). In our study, it was observed that high BW selection applied to males in both dam and sire lines not only increased BW in offsprings but also improved BW uniformity. In other words, more compact offsprings in terms of BW were obtained. Although this situation is seen as an advantage in providing uniformity in the next generation, it was determined that the BW variation decreased (Figure 1). In general, differences among BW groups in terms of FCR at 7, 14, 21 and 42 days of age were significant $(p<0.05)$, but not significant at 28 and 35 days of age. At 7 days of age, the best FCR was in A13 chicks, followed by $A 12$ and $A 11$; with 1.101, 1.232 and 1.271, respectively. At 14, 21, and 42 days of age, A13 and A11 showed the best FCR values. At the same age periods, A12 had worse FCR (Table 4).

There was no difference in FCR between BW groups in sire line at all ages except at 7 days of age. The best FCR value was found to be 1.29 in the B11 group, while a similar FCR was observed in the B12 and B13 groups at 7 days of age. Although the best FCR from 28 to 42 days of age was numerically achieved in the B13 group, this was not statistically significant (Table 5).

Feed conversion ratio (FCR) is one of the most common methods used to determine feed efficiency. It is defined as the amount of feed consumed per unit BW. FCR is a trait that shows genetic variation and can be improved by breeding and selection (Chambers \& Lin 1988; Kubiak et al., 2017). According to our study results, it is seen that the selection of the dam line males according to the BW level affects the FCR of the offsprings. Offsprings of dam line males with average and higher than average BW had better FCR 
Table 4 - Effects of BW selection in dam line males at 6 and 12 weeks on offsprings FCR.

\begin{tabular}{lcccccc}
\hline BW groups & $7 \mathrm{~d}$ & $14 \mathrm{~d}$ & $21 \mathrm{~d}$ & $28 \mathrm{~d}$ & $35 \mathrm{~d}$ & $42 \mathrm{~d}$ \\
\hline $\mathrm{A} 11$ & $1.271^{\mathrm{a}}$ & $1.262^{\mathrm{b}}$ & $1.345^{\mathrm{b}}$ & 1.450 & 1.599 & $1.697^{\mathrm{b}}$ \\
$\mathrm{A} 12$ & $1.232^{\mathrm{b}}$ & $1.379^{\mathrm{a}}$ & $1.416^{\mathrm{a}}$ & 1.533 & 1.642 & $1.877^{\mathrm{a}}$ \\
$\mathrm{A} 13$ & $1.101^{\mathrm{c}}$ & $1.238^{\mathrm{b}}$ & $1.323^{\mathrm{b}}$ & 1.476 & 1.612 & $1.666^{\mathrm{b}}$ \\
SEM & 0.027 & 0.023 & 0.015 & 0.018 & 0.013 & 0.037 \\
F value & 25.67 & 41.87 & 39.00 & 2.53 & 0.87 & 9.89 \\
\hline$p$ value & 0.000 & 0.000 & 0.000 & 0.160 & 0.466 & 0.013 \\
\hline
\end{tabular}

A11: Chickens from males with average BW; A12: Chickens from males with low BW; A13: Chickens from males with high BW; EW: Egg weight; CW: Chick weight; d: days of age.

a.b,c: The differences between the means shown with different letters in the same column are significant.

Table 5 - Effects of BW selection in sire line males at 6 and 12 weeks on offsprings FCR.

\begin{tabular}{lcccccc}
\hline BW groups & $7 d$ & $14 d$ & $21 d$ & $28 d$ & $35 d$ & $42 d$ \\
\hline B11 & $1.29^{b}$ & 1.38 & 1.38 & 1.53 & 1.67 & 1.76 \\
B12 & $1.31^{\mathrm{a}}$ & 1.32 & 1.38 & 1.44 & 1.65 & 1.74 \\
B13 & $1.30^{\mathrm{a}}$ & 1.32 & 1.42 & 1.48 & 1.63 & 0.71 \\
SEM & 0.003 & 0.016 & 0.009 & 0.023 & 0.021 & 0.019 \\
F value & 17.11 & 2.249 & 1.096 & 1.196 & 0.273 & 0.624 \\
\hline$p$ value & 0.003 & 0.187 & 0.393 & 0.365 & 0.770 & 0.567 \\
\hline
\end{tabular}

B11: Chickens from males with average BW, B12: Chickens from males with high BW, B13: Chickens from males with the highest BW; EW: Egg weight; CW: Chick weight; d: days of age.

$a, b:$ The differences between the means shown with different letters in the same column are significant.

values (Table 4). Offsprings of A13 males showed $11.20 \%$ better FCR than $A 12$, and $9.59 \%$ than $A 11$. It is understood that the selection applied for BW does not affect the feed consumption of offsprings much, and the increase in BW improves the FCR level. Even though the offsprings of heavier males in sire line showed better feed efficiency numerically, this did not occur to a significant level. However, the offsprings of B13 males had 2.84\% better FCR than B11 and 1.71\% better than B12 offsprings. The lack of difference in FCR between the sire line BW selection groups is thought to be due to the close BW between the groups.

As a result, it was determined that although twostage BW selection was applied to the dam and sire lines at 6 and 12 weeks of age, the variation between the selected ones continued. Taking advantage of this variation, it was observed that by selecting males with higher BW, heavier offsprings were obtained. However, BW variation in offsprings decreased. By preserving the variation at a certain level in future generations, a serious improvement can be achieved in the BW and FCR by selecting heavier males.

\section{ACKNOWLEDGEMENTS}

Authors thank the technical and administrative staff working at "Eskişehir Geçit Kuşağı Agricultural Research Institute", where breeding and selection applications of Anadolu-T broiler pure-lines were carried out.

\section{REFERENCES}

Calus MP, Vandenplas J, Hulsegge I, Borg R, Henshall JM, Hawken R. Assessment of sire contribution and breed of origin of alleles in a threeway crossbred broiler dataset. Poultry Science 2019;98(12):6270-6280.

Chambers JR, Lin CY. Age-constant versus weight-constant feed consumption and efficiency in broiler chickens. Poultry Science 1988;67(4):565-576.

Falconer D, Mackay TF. Introduction to quantitative genetics. 4th ed Longman;1996.

Flisar T, Malovrh Š, Terčič D, Holcman A, Kovač M. Thirty-four generations of divergent selection for 8-week body weight in chickens. Poultry Science 2014;93(1):16-23.

Hartcher KM, Lum HK. Genetic selection of broilers and welfare consequences: a review. World's Poultry Science Journal 2020; 76(1):154-167.

Jiang RS, Yang N. Effect of day-old body weight on subsequent growth carcass performances and levels of growth-related hormones in quality meat-type chicken. Archiv fur Geflugelkunde 2007;71(2):93-96.

Kubiak E, Wimmers K, Reyer H, Szwaczkowski T. Genetic aspects of feed efficiency and reduction of environmental footprint in broilers:a review. Journal of Applied Genetics 2017;58(4):487-498.

Leeson S, Summers JD. Broiler breeder production. Nottingham: Nottingham University Press; 2010.

Mebratie W, Madsen P, Hawken R, Rome H, Marois D, Henshall J, et al. Genetic parameters for body weight and different definitions of residual feed intake in broiler chickens. Genetic Selection Evolution 2019;51:53.

Muth PC, Zárate AV. Breast meat quality of chickens with divergent growth rates and its relation to growth curve parameters. Archiv fuer Tierzucht 2017;60(4):427.

Sorensen P. Study of the effect of selection for growth in meat type chickens [PhD dissertation]. Copenhagen: Beretning fra Statens Husdyrbrugsforsoege; 1986. 
Sutherland DAAT, Honaker CF, Dorshorst B, Andersson L, Brisbin Jr IL, Siegel $P B$. Growth patterns for three generations of an intercross between red junglefowl and chickens selected for low body weight. Journal of Animal Breeding and Genetics 2018;135(4):300-310.

Tallentire CW, Leinonen I, Kyriazakis I. Breeding for efficiency in the broiler chicken:a review. Agronomy for Sustainable Development 2016;36:66.

Türkoğlu M, Sarıca M. "Tavuk Genetiği ve ıslahı" Tavukçuluk Bilimi, Yetiştirme, Besleme, Hastalıklar. Ankara: Editörler M.Türkoğlu, M.Sarıca; 2018. p.354-404.
Ucar A. The effect of some parent stock characteristics on incubation and broiler performance [PhD dissertation]. Ankara: Ankara University; 2020

Van Grevenhof I, Van der Werf J. Design of reference populations for genomic selection in crossbreeding programs. Genetic Selection Evolution 2015;47:14.

Wilson HR. Interrelationships of egg size, chick size, posthatching growth and hatchability. World's Poultry Science Journal 1991;47:5-20. 